\title{
CURING DEPTH AND DEGREE OF CONVERSION OF DIFFERENT NANO-HYBRID COMPOSITES
}

\author{
Mohammad Wannous, Souad A. Abboud \\ Department of Operative Dentistry, Damascus University, Syria
}

\begin{abstract}
INTRODUCTION: The increasing use of composite resin as a posterior restorative material puts it under constant masticatory stresses. Depth of cure, considered as the most important factor helps resist these stresses.

OвJECTIVEs: The aim of the study was to assess the curing depth and degree of conversion of four different nano-hybrid composites (two conventional methacrylate and two pure Ormocer composites), using ISO 4049 digital caliper and micro-hardness test.

MATERIAL AND METHODS: 20 cylindrical composite samples per group were created using Admira Fusion $\mathrm{x}$-tra (Admira Fusion; VOCO GmbH, Cuxhaven, Germany) and Tetric N-Ceram Bulk Fill (Ivoclar Vivadent; Schaan, Liechtenstein) composites. Curing depth was calculated using ISO 4049 digital caliper, and micro-hardness test was applied to assess degree of conversion of all composites using digital micro-Vickers hardness tester (Galileo LTF; Italy). 20 seconds of curing was performed with curing LED unit (Guilin Woodpecker Medical Instrument Co., Ltd.; China), with a light intensity of $1,000 \mathrm{mw} / \mathrm{cm}^{2}$. A statistical analysis was done using SPSS, version 17 , and the results were compared with one-way and multiple-way analysis of variance (ANOVA). $P$-value $<0.05$ was considered statistically significant.

RESUlTs: Average curing depth of Tetric N-Ceram was $1.60 \mathrm{~mm}( \pm 0.09)$, with mean micro-hardness of 78.17\%. Tetric N-Ceram Bulk Fill mean curing depth was $2.76 \mathrm{~mm}( \pm 0.18)$, and micro-hardness of $73.97 \%$. Admira Fusion x-tra showed $2.92 \mathrm{~mm}( \pm 0.15)$ as mean depth of cure and $80.20 \%$ of micro-hardness, while for Admira Fusion it was $1.71 \mathrm{~mm}( \pm 0.19)$, with micro-hardness of $80.605 \%$.

ConcLusions: All the tested materials showed acceptable results according to ISO 4049 test. Only Admira Fusion and Admira Fusion x-tra accomplished micro-hardness tests.
\end{abstract}

KEY wORDS: depth of cure, micro-hardness, Ormocer, composite resin.

J Stoma 2021; 74, 3: 147-152

DOI: https://doi.org/10.5114/jos.2021.108839

\section{INTRODUCTION}

The increasing use of composite resin as a posterior restorative material apply constant stress in mastication. Considered as the most important factor, depth of cure helps to avoid this stress and is a key to clinical success of composite resin restorations [1]. However, insufficient curing of deep layers of composite affects the chemical and physical qualities of composite resins, including discoloration, wear resistance, and water absorption. Moreover, the possible dissolution of non-interacting elements may result in biologically harmful effects and bonding defects between tooth and restoration [2].

Both curing depth and conversion degree of composite resins can be measured either directly or indirectly [3]. Direct methods for depth of cure measurement, which

\section{JOURNAL OF} STOMATOLOGY CZASOPISMO STOMATOLOGICZNE

ADDRESS FOR CORRESPONDENCE: Dr. Mohammad Wannous, Department of Operative Dentistry, Damascus University, Syria, e-mail: wannousmohammad@gmail.com 
depend on infrared spectrometry to measure the degree of monomer conversion, are not common in research tests [4]. But indirect ones, such as scrape abrasion testing, according to ISO standards and Vickers \& Knoop hardness tests, are the most common [1].

Hardness is defined as the capability of material to resist penetration, along with determining material's resistance to wear and abrasion [5]. Hardness values properly coincide with the degree of monomer conversion and depth of cure $[5,6]$. Generally, determining the depth of cure requires measuring of the ratio of bottom/top hardness. Majority of studies have implemented $80 \%$ of bottom/top hardness ratio, and demonstrated clinically recognized depth of cure of tested material $[8,9]$. The percentage and form of filler particles play a key role in surface hardness [6].

There are many factors, which may affect the curing depth of restorative materials used. Those associated with material involve organic and inorganic matrix as well as composite shade and quantity of photo initiators. Those related to a dentist include distance and orientation of light unit, restorative technique, and types of light curing devices, and regarding emission spectrum and relation between light intensity, time of exposure and status of used tools [10].

In order to reduce unwanted damage of restorative material, depth of cure should reach its highest thickness [10]. $2 \mathrm{~mm}$ thick increments are clinically accepted for layered composite resins [11]. However, using layering technique in restoring deep cavity with an increments of $2 \mathrm{~mm}$ in thickness, may increase possibility of air bubble inclusion or contamination between the layers.

Some dental supplies manufacturers have recently presented bulk-fill resin composites, claiming that they can be placed and polymerized appropriately in $4 \mathrm{~mm}$ bulks [12]. To ensure proper polymerization in deep cavities, manufacturers used different methods, including introducing new and more interactive photo-initiator specimens, decreasing the opacity of composite resins (via changing filler content, such as increasing the size of particles), in addition to reducing the incompatibility between filler particles and resin matrix [13]. An increase in translucency of some composite resins can be noted during clinical use. One of the latest developments is nano-hybrid organically modified ceramics (Ormocer).

Based on an inorganic base containing silicon dioxide $\left(\mathrm{SiO}_{2}\right)$ and polymerizable organic components, Ormocer combines the hardness of glass and resin properties. The purpose of using this material, which has the color of a tooth, is to improve not only aesthetics, but also wear resistance that allows reduce polymerization shrinkage and surface roughness. Moreover, it protect the teeth against any prospective secondary caries. Ormocer does not contain Bis-GMA resin (bisphenol A-glycidyl methacrylate) or any other kind of conventional methacrylates, which helps to eliminate any concerns with cytotoxicity; Ormocer improves biocompatibility because it is considered idle [14].

\section{OBJECTIVES}

This study aimed to assess the curing depth and degree of conversion of four different nano-hybrid composites (two conventional methacrylate and two pure Ormocer composites), using ISO 4049 digital caliper and micro-hardness test.

\section{MATERIAL AND METHODS}

In total, 80 cylindrical laboratory samples of four different composite materials (Table 1 ) were created. There were equally $(n=20)$ divided into four different groups of composites, including Tetric N-Ceram (group A), Tetric N-Ceram Bulk Fill (group B), Admira Fusion $\mathrm{x}$-tra (group C), and Admira Fusion (group D). A1 shade was used for both Tetric N-Ceram and Admira Fusion

TABLE 1. Composites used in paper

\begin{tabular}{|c|c|c|c|c|c|}
\hline Group & Composite & Composition & Viscosity and increment size & Shade & Manufacturer \\
\hline A & Tetric N-Ceram & $\begin{array}{l}\text { Matrix: Bis-GMA/Bis-EMA/UDMA/additives/ } \\
\text { initiators/stabilizers/pigments } \\
\text { Filler 61-78\%: Barium-aluminosilicate glass, } \\
\text { prepolymer (isofillers), ytterbium trifluoride }\end{array}$ & $\begin{array}{l}\text { High viscosity, bulk fill, } \\
\text { up to } 4 \mathrm{~mm}\end{array}$ & A1 & $\begin{array}{l}\text { voco, Cuxhaven, } \\
\text { Germany }\end{array}$ \\
\hline B & $\begin{array}{l}\text { Tetric N-Ceram } \\
\text { Bulk Fill }\end{array}$ & $\begin{array}{l}\text { Matrix 61-78\%: Bis-GMA/Bis-EMA/UDMA/ } \\
\text { additives/initiators/stabilizers/pigments } \\
\text { Filler 61-78\%: Barium-aluminosilicate glass, } \\
\text { prepolymer (isofillers), ytterbium trifluoride }\end{array}$ & $\begin{array}{l}\text { High viscosity, bulk fill, } \\
\text { up to } 4 \mathrm{~mm}\end{array}$ & IVA & $\begin{array}{l}\text { Ivoclar Vivadent, Schaan, } \\
\text { Liechtenstein }\end{array}$ \\
\hline$C$ & $\begin{array}{l}\text { Admira Fusion } \\
\text { x-tra }\end{array}$ & $\begin{array}{l}\text { Matrix: Ormocer - organically modified silicic acid } \\
\text { Filler 69-84\%: Barium-aluminum glass, } \\
\text { pyrogenic silicon dioxide }\end{array}$ & $\begin{array}{l}2 \mathrm{~mm} \text { for incremental } \\
\text { filling technique }\end{array}$ & U & $\begin{array}{l}\text { VOCO, Cuxhaven, } \\
\text { Germany }\end{array}$ \\
\hline D & Admira Fusion & $\begin{array}{l}\text { Matrix: Ormocer - organically modified silicic acid } \\
\text { Filler 69-84\%: Barium-aluminum glass, } \\
\text { pyrogenic silicon dioxide }\end{array}$ & $\begin{array}{l}2 \mathrm{~mm} \text { for incremental } \\
\text { filling technique }\end{array}$ & $\mathrm{A} 1$ & $\begin{array}{l}\text { Ivoclar Vivadent, Schaan, } \\
\text { Liechtenstein }\end{array}$ \\
\hline
\end{tabular}


composites after using VITA Easyshade ${ }^{\circledR}$ Advance 4.0 spectrophotometer to determine the exact color of Admira Fusion x-tra universal shade and IVA shade of Tetric N-Ceram bulk fill. Samples were prepared with dimensions of $8 \mathrm{~mm}$ high and $4 \mathrm{~mm}$ in diameter, using a mold of dark Teflon. The Teflon mold was positioned on a glass plate covered with a celluloid bolster. Cylindrical mold was filled with the material to be studied. A celluloid bolster covered the upper mold opening, and then, each sample was cured for 20 seconds by LED light curing unit (LED. C, Guilin Woodpecker Medical Instrument Co. Ltd.; China) with tip diameter of $8 \mathrm{~mm}$, light intensity of $1,000 \mathrm{mw} / \mathrm{cm}^{2}$, and wavelength range of 420-480 $\mathrm{nm}$. The head of the device head was in complete contact with the surface of the mold to ensure that all samples were exposed to the same angle of light. The intensity of the curing unite was checked before curing each sample with DENTAMERICA light cure power intensity meter (DENTAMERICA; CA, USA).

\section{DOC ${ }^{150}$ MEASUREMENT}

After curing, the specimens were removed from the mold, and curing depth was obtained according to ISO 4049 depth of cure method, after the unreacted composite material was scrapped off with a plastic spatula. This procedure left the samples with different lengths. The absolute length $(\mathrm{AL})$ of cylindrical samples of the cured composite was then measured by digital calliper with $\pm 0.01 \mathrm{~mm}$ accuracy (Qingdao Tide Machine Tool Supply Co. Ltd., China). The absolute length was divided by 2 , and the latter obtained value was recorded as DOC ${ }^{\mathrm{ISO}}$.

\section{DC ${ }^{\text {VHN }}$ MEASUREMENT}

After recording curing depth according to ISO 4049 standards, the top surface of the sample was marked to differentiate from its bottom surface. The length of all samples was united using diamond finishing bur at the bottom surface of the sample, far from the curing light. The samples were returned to standard molds, with $5 \mathrm{~mm}$ length for bulk-filled composites and $2 \mathrm{~mm}$ for incremental composites, and the bottom surface was flatted with a diamond finishing bur to acquire the same length for all the samples. To determine the degree of conversion of studied materials at these lengths, micro-hardness was tested on both surfaces of each sample using digital micro-Vickers hardness tester (Galileo LTF; Italy). The samples were placed under indenter of the micro-hardness tester, and surfaces' micro-hardness of the samples were determined using a load of $200 \mathrm{~g}$ for 15 seconds. Micro-hardness values for the top surface of each sample ( $\mathrm{SH})$ and its bottom surface $(\mathrm{BH})$ were used to calculate the conversion degree of each sample $\mathrm{DC}^{\mathrm{VHN}}$ according to the following equation:

$$
\mathrm{DC}^{\mathrm{VHN}}=(\mathrm{BH} / \mathrm{SH}) \times 100 \% \text {. }
$$

\section{STATISTICAL ANALYSIS}

SPSS software version 17 (SPSS, Chicago, IL, USA) was applied for statistical analysis. The mean and standard deviation (SD) were calculated with this software, and the outcomes were compared through one-way and multiple-way analysis of variance (ANOVA), with $p$-value $<0.05$ considered statistically significant.

\section{RESULTS}

As shown in Table 2, Tetric N-Ceram revealed the lowest depth of cure according to ISO 4049 test, while Admira Fusion $\mathrm{x}$-tra showed the highest depth for the same test.

As for the surface micro-hardness test, both pure Ormocer composites (Admira Fusion and Admira Fusion $\mathrm{x}$-tra) demonstrated a higher degree of conversion compared to methacrylate composites (Tetric N-Ceram and Tetric N-Ceram bulk fill).

Statistical analysis (Table 3) showed significant difference $(p<0.05)$ in ISO depth of cure between all composites, with Admira Fusion $\mathrm{x}$-tra indicating the highest and Tetric N-Ceram the lowest values. Table 4 demonstrates that significant difference was observed in $\mathrm{DC}^{\mathrm{VHN}}$ between nano-hybrid Ormocer composites and meth-

TABLE 2. Comparison of mean depth of cure values, and $(\mathrm{BH} / \mathrm{SH}) \times 100 \%$ formula calculations for all materials

\begin{tabular}{|c|c|c|c|c|c|c|c|c|c|}
\hline & & $n$ & Mean & Std. deviation & Std. error & Minimum & Maximum & $\mathbf{F}$ & $p$-value \\
\hline \multirow{4}{*}{$\mathrm{DOC}{ }^{150}$} & Tetric N-Ceram & 20 & 1.60950 & 022851. & 0.005110 & 1.590 & 1.681 & \multirow[t]{4}{*}{4815.580} & \multirow[t]{4}{*}{$0.000^{* *}$} \\
\hline & Tetric N-Ceram Bulk Fill & 20 & 2.76785 & 0.055607 & 0.012434 & 2.700 & 2.880 & & \\
\hline & Admira Fusion X-tra & 20 & 2.92275 & 0.043301 & 0.009682 & 2.840 & 2.990 & & \\
\hline & Admira Fusion & 20 & 1.71015 & 0.048862 & 0.010926 & 1.605 & 1.799 & & \\
\hline \multirow[t]{4}{*}{$D C^{\mathrm{VHN}}$} & Tetric N-Ceram & 20 & 78.17000 & 1.864657 & 0.416950 & 74.80 & 81.20 & \multirow[t]{4}{*}{85.957} & \multirow[t]{4}{*}{$0.000^{* *}$} \\
\hline & Tetric N-Ceram Bulk Fill & 20 & 73.97500 & 0.912414 & 0.204022 & 72.30 & 76.00 & & \\
\hline & Admira Fusion X-tra & 20 & 80.20500 & 1.215027 & 0.271688 & 78.10 & 82.00 & & \\
\hline & Admira Fusion & 20 & 80.60500 & 1.670952 & 0.373636 & 78.00 & 82.90 & & \\
\hline
\end{tabular}

\footnotetext{
*The mean difference is significant at the 0.05 level.
} 
TABLE 3. Multiple comparisons of DOC ${ }^{\text {ISO }}$

\begin{tabular}{|c|c|c|c|c|}
\hline & Tetric N-Ceram & Tetric N-Ceram Bulk Fill & Admira Fusion & Admira Fusion x-tra \\
\hline Tetric N-Ceram & & 0.00 & 0.00 & 0.00 \\
\hline Tetric N-Ceram Bulk Fill & 0.00 & & 0.00 & 0.00 \\
\hline Admira Fusion & 0.00 & 0.00 & & 0.00 \\
\hline Admira Fusion $x$-tra & 0.00 & 0.00 & 0.00 & \\
\hline
\end{tabular}

TABLE 4. Multiple comparisons of DCVHN

\begin{tabular}{|lc|c|c|c|}
\hline & Tetric N-Ceram & Tetric N-Ceram Bulk Fill & Admira Fusion & Admira Fusion $x$-tra \\
\hline Tetric N-Ceram & & 0.00 & 0.00 & 0.00 \\
\hline Tetric N-Ceram Bulk Fill & 0.00 & & 0.00 & 0.00 \\
\hline Admira Fusion & 0.00 & 0.00 & & 0.39 \\
\hline Admira Fusion $x$-tra & 0.00 & 0.00 & 0.39 \\
\hline
\end{tabular}

${ }^{*}$ The mean difference is significant at the 0.05 level.

acrylate nano-hybrid composites, with $p<0.05$. Even though Admira Fusion had the highest percentage and Tetric N-Ceram Bulk Fill had the lowest one, there was no difference between Admira Fusion and Admira Fusion $\mathrm{x}$-tra for the same test $(p>0.05)$.

\section{DISCUSSION}

The present study was comparing the curing depth of four different composite restorative materials in accordance with ISO 4049 standards, and surface Vickers hardness test was applied after unified laboratory conditions. The samples were prepared using dark mold to prevent light penetration and avoid any effects on the degree of conversion and curing depth.

Additionally, celluloid bolster was used on the mold edges after filling with the composite resin; a step that prevents Oxygen penetration or its' inhabitation, which leads to cure shrinkage [15]. Direct methods of curing depth measurement, such as infrared spectrometry and laser (Ramon), are considered complicated and

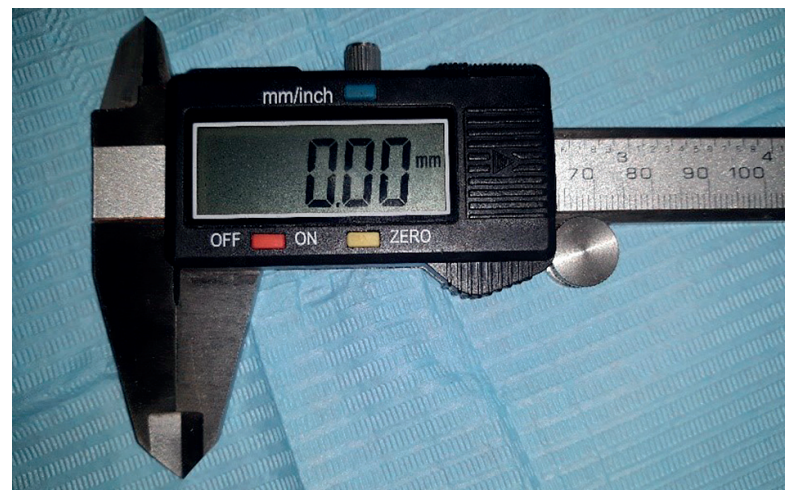

FIGURE 1. Digital calliper time-wasting, yet highly efficient. Indirect methods, such as scrape abrasion testing according to ISO standards and Vickers \& Knoop hardness tests are most commonly used in research investigating curing depth measurements $[16,17]$.

Some studies showed that scraping test (ISO 4049) provides exaggerated results in comparison to surface hardness test, which has been proven to detect conversion degree of composite resins, and its results comply with those achieved using infrared spectrometry [7, 17]. Increasing force load applied in surface hardness test significantly affects the registered values of surface hardness.

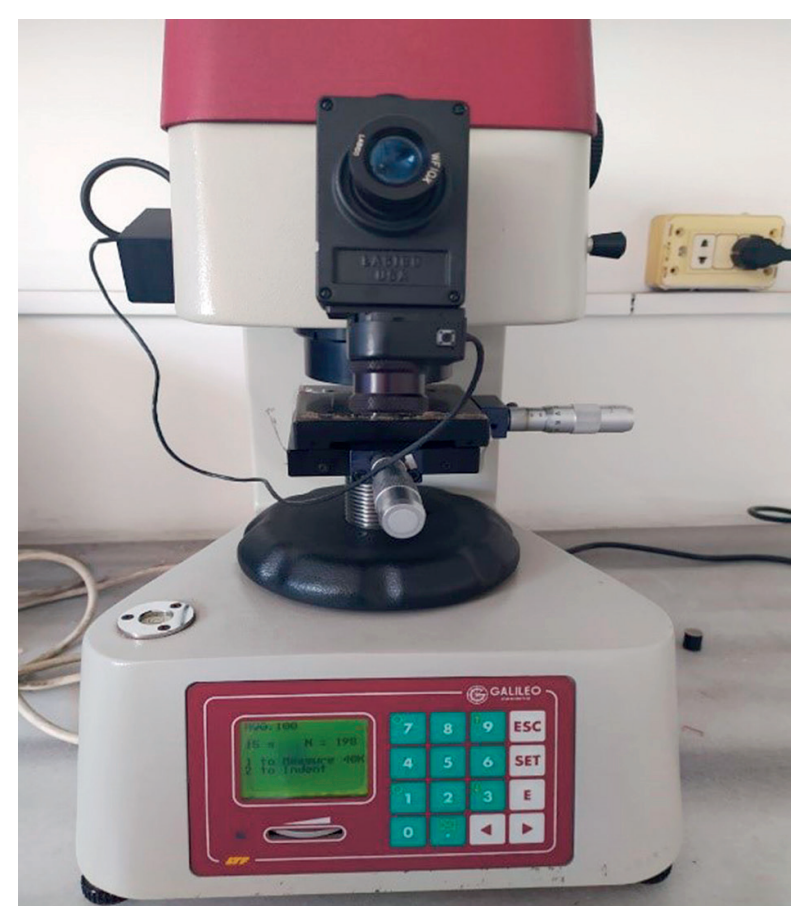

FIGURE 2. Microhardness tester 
Therefore, applied force should range between $1 \mathrm{~g}$ and $1 \mathrm{~kg}$, but the common range applied in these tests is between 100-500 g [18].

In this study, a $200 \mathrm{~g}$ force load was applied, with dwell time of 15 seconds. Results of Yoldaz study has shown that a 15 second dwell time can be accepted as actual time of load application limit for dental composite [19]. Curing light intensity and exposure time are the variables that significantly affect the depth of cure and hardness values [20]. In this study, the light was applied at an intensity of $1,000 \mathrm{mw} / \mathrm{cm}^{2}$ for 20 seconds in order to achieve a maximum curing at the same experimental conditions.

This study was conducted according to ISO 4049 test, and shown acceptable findings of the depth of cure for all the materials used. Also, the average curing depth of nano-hybrid Ormocer composites was significantly greater than the methacrylate composites. Bulkfilled composites demonstrated significantly higher depth of cure. These findings were in agreement with studies performed by Flury et al., and Jain et al., who stated that bulk fill composites presented greatest curing depth measurements when tested with ISO 4049 method [21, 22].

The great curing depth of bulk fill composites can be attributed to the increase of their content with conventional photo initiators as well as germanium photo initiators and its greater ability to absorb blue light [16], in addition to high translucency, which is another catalyst for increasing depth of cure $[23,24]$.

Bucuta and his colleagues found that translucency reduces scattering of light, which helps light-curing of deeper layers [25]. Given the fact that the efficiency of light scattering increases in small-size filling particles $[7,16]$, this could explain the increase of depth of cure in Admira Fusion x-tra specimens, where the filling particle size ranged between 1-10 $\mu \mathrm{m}$ (average, 6) as compared to Tetric N-Ceram Bulk Fill with particle size range between $0.1-5 \mu \mathrm{m}$.

Both Tetric N-Ceram and Tetric N-Ceram Bulk Fill demonstrated unacceptable degree of conversion according to Vickers test, while Admira Fusion and Admira Fusion x-tra showed the opposite. This might be due to the fact that Ormocer encompasses inorganic-organic co-polymers with inorganic silanated fillers. Sol-gel technique creates hydrolysis and condensation of alkoxides, an inorganic Si-O-Si network formed by a long inorganic silica chain cornerstone with organic lateral chains, which can react during polymerization procedure using conventional photo-initiators [26].

Filler size and greater content in dental resins was established in order to improve the raise of surface hardness of composites. In shaded composites, the existence of colorants can influence curing depth, because of its restricted light infiltration and decrease of polymerization degree at deeper levels, as colorants are opaque particles [27]. All these factors may explain the higher degree of conversion of Admira Fusion and Admira Fusion $\mathrm{X}$-tra composites.

In this study, a decrease in surface hardness associated with an increase in thickness was observed, and this result is consistent with numerous previous studies showing a decrease in hardness during thickness increase [10]. This is attributed to a larger light transmittance in layers of less thickness, which leads to a greater degree of conversion in composite resin as well as an increase in roughness of the surface material.

\section{CONCLUSIONS}

Within the limitations of this study, all the investigated composites presented acceptable depth of cure according to ISO 4049 test using both incremental or bulk fill techniques, but the surface hardness of nano-hybrid Ormocer composite was significantly better compared to methacrylate nano-hybrid composite. However, Admira Fusion and Admira Fusion x-tra demonstrated better micro-hardness compared to Tetric N-Ceram and Tetric N-Ceram Bulk Fill composites, with higher depth of cure as per ISO 4049 standards.

\section{CONFLICT OF INTEREST}

The authors declare no potential conflicts of interest with respect to the research, authorship, and/or publication of this article.

\section{References}

1. Parasher A, Ginjupalli K, Somayaji K, Kabbinale P. Comparative evaluation of the depth of cure and surface roughness of bulk-fill composites: an in vitro study. Dent Med Probl 2020; 57: 39-44.

2. Finger W, Kanehira M, Araki Y, Wada T, Utterodt A, Komatsu M. Curing depth of light-activated nanofiller containing resin composites. World J Dent 2012; 3: 119-125.

3. Theobaldo JD, Aguiar FHB, Pini NIP, Lima DANL, Liporoni PCS, Catelan A. Effect of preheating and light-curing unit on physicochemical properties of a bulk fill composite. Clin Cosmet Investig Dent 2017; 9: 39-43

4. Sartori N, Knezevic A, Peruchi LD, Phark JH, Duarte S Jr. Effects of light attenuation through dental tissues on cure depth of composite resins. Acta Stomatol Croat 2019; 53: 95-105.

5. Mohammadi N, Alavi FN, Rikhtehgaran S, et al. Effect of bleaching method and curing time on the surface microhardness of microhybrid composite resin. Maedica (Bucur) 2020; 15: 359-364.

6. Al-Mansour K, Al-Sada A, Al-Sinan H. Curing depth of bulk-fill composites - an in-vitro study. Pakistan Oral \& Dental Journal 2015; 35: 270-274.

7. Garoushi S, Vallittu P, Shinya A, Lassila L. Influence of increment thickness on light transmission, degree of conversion and micro hardness of bulk fill composites. Odontology 2016; 104: 291-297.

8. Roy KK, Kumar KP, John G, Sooraparaju SG, Nujella SK, Sowmya K. A comparative evaluation of effect of modern-curing lights and curing modes on conventional and novel-resin monomers. J Conserv Dent 2018; 21: 68-73.

9. Price RB, Felix CA, Andreou P. Evaluation of a dual peak third generation LED curing light. Compend Contin Educ Dent 2005; 26: 331-348. 
10. Yokesh CA, Hemalatha P, Muthalagu M, Justin MR. Comparative evaluation of the depth of cure and degree of conversion of two bulk fill flowable composites. J Clin Diagn Res 2017; 11: ZC86-ZC89.

11. Craig R, Powers J, Sakaguchi R. Craig's Restorative Dental Materials. $12^{\text {th }}$ ed. St. Louis: Mosby; 2006: 206.

12. Rouhollahi M, Mohammadibasir M, Talim Sh. Comparative depth of cure among two light-cured core build-up composites by surface vickers hardness. J Dent (Tehran) 2012; 9: 255-261.

13. Dionysopoulos D, Tolidis K, Gerasimou P. The effect of composition, temperature and post-irradiation curing of bulk fill resin composites on polymerization efficiency. Materials Res 2016; 19: 466-473.

14. Rajeev V, Arunachalam R, Nayar S, Arunima PR, Ganapathy S, Vedam V. "Ormocer an innovative technology": a replacement for conventional cements and veneer? A comparative in vitro analysis. Eur J Dent 2017; 11: 58-63.

15. Nagi SM, Moharam LM, Zaazou MH. Effect of resin thickness, and curing time on the micro-hardness of bulk-fill resin composites. J Clin Exp Dent 2015; 7: e600-e604. doi: 10.4317/jced.52536.

16. Tsuzuki FM, de Castro-Hoshino LV, Lopes LC, Sato F, Baesso ML, Terada RS. Evaluation of the influence of light-curing units on the degree of conversion in depth of a bulk-fill resin. J Clin Exp Dent 2020; 12: e1117-e1123. doi: 10.4317/jced.57288.

17. Son SA, Roh HM, Hur B, Kwon YH, Park JK. The effect of resin thickness on polymerization characteristics of silorane-based composite resin. Restor Dent Endod 2014; 39: 310-318.

18. Uhl A, Michaelis C, Mills R, Jandt K. The influence of storage and indenter load on the Knoop hardness of dental composites polymerized with LED and halogen technologies. Dental Materials 2004; 20: 21-28

19. Yoldas O, Akova T, Uysal H. Influence of different indentation load and dwell time on Knoop microhardness tests for composite materials. Polym Test 2004; 23: 343-346.

20. Shirazinia M, Mehmandoost-Khajeh-Dad AA, Dehghani V, Mehmandoost-Khajeh-Dad J, Khaghani M. The effect of curing light intensity on free volume size in some dental composites. Polim Med 2016; 46: 129-133.

21. Flury S, Hayoz S, Peutzfeldt A, Hüsler J, Lussi A. Depth of cure of resin composites: Is the ISO 4049 method suitable for bulk fill materials? Dental Materials 2012; 28: 521-528.

22. Jain A, Aggarwal N, Gupta H, Abrol A, Singh C, Rapgay T. The comparative evaluation of depth of cure of bulk-fill composites - an in vitro study. Journal of Conservative Dentistry 2019; 22: 371.

23. Borges BC, Bezerra GV, Mesquita Jde A, et al. Effect of irradiation times on the polymerization depth of contemporary fissure sealants with different opacities. Braz Oral Res 2011; 25: 135-142.

24. Polydorou O, Manolakis A, Hellwig E, Hahn P. Evaluation of the curing depth of two translucent composite materials using a halogen and two LED curing units. Clin Oral Investig 2007; 12: 45-51.

25. Bucuta S, Ilie N. Light transmittance and micro-mechanical properties of bulk fill vs. conventional resin based composites. Clin Oral Investig 2014; 18: 1991-2000.

26. Lins R, Vinagre A, Alberto N, et al. Polymerization shrinkage evaluation of restorative resin-based composites using fiber bragg grating sensors. Polymers (Basel) 2019; 11: 859.

27. Yokesh CA, Hemalatha P, Muthalagu M, Justin MR. Comparative evaluation of the depth of cure and degree of conversion of two bulk fill flowable composites. J Clin Diagn Res 2017; 11: ZC86ZC89. DOI: 10.7860/JCDR/2017/28004.10444. 